\title{
FERRAMENTA DE APOIO AO DESENVOLVIMENTO SENSÓRIO-MOTOR DE DEFICIENTES
}

Rodrigo de Camargo Bueno - rodrigo.cb2@puccampinas.edu.br

Faculdade de Engenharia Mecânica

Amilton da Costa Lamas - amilton@puc-campinas.edu.br

Faculdade de Engenharia Elétrica

Pontifícia Universidade Católica de Campinas,

Rua Professor Dr. Euryclides de Jesus Zerbini, 1516

13087-571 - Campinas - SP

Resumo: Dificuldades de motricidade, cognição, mobilidade e destreza com os membros superiores são encontrados em alguns deficientes visuais com baixa visão e na maioria dos deficientes físicos com paralisia cerebral. A superação destes desafios requer o apoio de instituições especializadas em reabilitação física capazes de realizarem uma avaliação do grau de comprometimento da deficiência e estabelecer programas de treinamento motor/cognitivo. Via de regra os equipamentos com esta finalidade são extremamente caros para instituições resultando na falta de ferramentas adequadas. Este trabalho relata o desenvolvimento da prova de conceito de uma ferramenta de baixo custo para apoio à reabilitação sensório-motora de deficientes. $O$ planejamento da ferramenta, desenvolvimento, testes e validação foram realizados de forma colaborativa com duas instituições campineiras que prestam serviços às pessoas com alguma deficiência visual, motora elou cognitiva, o Centro Cultural Louis Braille de Campinas e a Therapies Serviços de Fisioterapia. A prova de conceito concebida consiste de dois cubos interativos via WiFi formado por células de cores ajustáveis com sequência programável. A avaliação e posterior apoio aos programas de reabilitação das deficiências sensório-motoras é feita através de gamificação de exercícios. Por estas características foi apelidada de ModalCube após pesquisa entre os técnicos especialistas e assistidos das instituições. A ferramenta é resultado da problematização quanto as dificuldades $e$ necessidades dos deficientes realizada junto aos técnicos especialistas e assistidos das duas instituições parceiras.

Palavras-chave: deficiência. desenvolvimento sensório-motor. extensão universitária. paralisia cerebral. trabalho colaborativo.

\section{INTRODUÇÃO}

Segundo o senso de 2010 do Instituto Brasileiro de Geografia e Estatística (IBGE,2010) existem Brasil mais de 45,6 milhões de pessoas com alguma deficiência, das quais 6,5 milhões possuem deficiência visual, e, dentre estas, 583 mil são totalmente cegas e 6 milhões possuem baixa visão, isto é, alguma dificuldade para enxergar. Por outro lado, dentre os 45,6 milhões de pessoas existem casos de crianças com paralisia cerebral que foram incluídas no gráfico de quantidade de deficientes físicos deste censo. De qualquer forma se estima que existam 1 milhão de pessoas com deficiências físicas no Brasil. Importante ressaltar que, apesar do menor 
número de crianças deficientes com paralisia cerebral, as limitações impostas por esta condição são extremas, tornando-as completamente dependentes dos adultos, via de rega seus familiares.

\subsection{Cenário atual}

A acessibilidade para deficientes é muito baixa, muitas vezes lanchonetes, hotéis, empresas, shoppings, calçadas, entre outros estabelecimentos não possuem acessibilidade, dificultando a vida dos mesmos, e quando existe não está dentro das normas (BRASIL, 1989 e BRASIL, 1999). Ao buscar pela introdução desse público dentro da sociedade, as medidas de inclusão se baseiam em interesses governamentais para os direitos humanos, fundamentais e individuais (que prezam pela autonomia e respeito à pessoa humana, proteção, igualdade e liberdade) e nos trabalhos assistivos promovidos por instituições que contribuem para o desenvolvimento de personalidade e potenciais do indivíduo. Qualquer ação visando a inclusão social ou mesmo que se dedique apenas em tornar a vida mais digna desta parcela da população só é efetiva se, simultaneamente, ocorrerem iniciativas para promoção do desenvolvimento sensório-motor (NOVAC, I, 2014 e BRANDÃO, MB, 2014). As ferramentas assistivas usadas com o deficiente físico e/ou cognitivo é uma das alternativas que promovem o desenvolvimento de habilidades que são de uso comum na realização das tarefas diárias dentro de casa ou no trabalho.

Deficientes visuais com baixa visão e alguns deficientes físicos com paralisia cerebral ou apenas com idade avançada precisam de treinamento visual com objetivo de desenvolver as capacidades visuais e promover o desenvolvimento cognitivo (FELICETTI S. e SANTOS E., 2016). Isto é feito, com exercícios que utilizam objetos coloridos de alto contraste e com diferentes texturas. Este método é bastante eficiente visto que combina o uso de diferentes sentidos no processo de cognição e reconhecimento dos objetos, no entanto, não tem muita versatilidade, por ser um processo essencialmente estático. Além disto, este método requer que a instituição de apoio tenha extensa biblioteca de objetos de forma a estimular os pacientes, pois com o tempo acabam cansando de alguns métodos de reabilitação pela monotonia.

\subsection{Extensão na PUC-Campinas}

A Pontifícia Universidade Católica de Campinas (PUC-Campinas) tem como missão produzir, sistematizar e socializar o conhecimento, por meio de atividades de ensino, pesquisa e extensão, visando à capacitação profissional de excelência, à formação integral da pessoa humana e à contribuição de uma sociedade justa e solidária. A universidade tem qualificado suas ações extensionistas dando oportunidades aos seus professores de ingressarem num plano de carreira de extensão com 40 horas semanais. Esta realidade implica no envolvimento de parceiros diretos e dezenas de alunos, dos mais variados cursos, permitindo à extensão ser uma atividade rica em aprendizagens significativas. Para os parceiros se privilegia a troca, através de oficinas socioeducativas há intenso enlace entre as demandas da comunidade e o desenvolvimento do projeto, sempre pautado em uma situação-problema.

Nesta troca a Universidade chega aos diferentes lugares da região metropolitana, aprende com eles, interage, apresenta soluções sempre adequadas à realidade vivida e constrói as bases para garantir a autonomia dos envolvidos. A garantia da autonomia é fundamental, pois se entende que a comunidade envolvida precisa conhecer seus desafios, se posicionar diante deles e gerir suas expectativas. Assim, a extensão se refaz num ciclo positivo e interativo; positivo porque todos aprendem, interativo porque é na soma de diferentes conhecimentos que se encontra soluções, às vezes, bem próximas às comunidades e aos seus anseios. 


\subsection{Oportunidade/Objetivo}

Estes argumentos iniciais demonstram a existência de excelente oportunidade para combinar as atividades de extensão no sentido de, através de recursos dialógicos, levar aos deficientes com comprometimento sensório-motor, em especial àqueles pertencentes às comunidades em fragilidade social da cidade de Campinas, uma solução de Engenharia Elétrica de baixo custo que promova o desenvolvimento das capacidades cognitivas. Idealizou-se um plano de trabalho de extensão com objetivo de desenvolver uma prova de conceito de um jogo que permitisse a realização de exercícios sensório-motores para indivíduos com comprometimento de motricidade.

A prova de conceito do jogo foi desenvolvida segundo o plano de trabalho de aluno de extensão "Sistema para desenvolvimento sensório-motor", associado ao Plano de Trabalho de Extensão "Engenharia Elétrica e a Inclusão Social/Digital de Deficientes" do prof. Amilton da Costa Lamas. Ela é uma prova de conceito de um jogo composto por dispositivos multissensoriais de apoio ao treinamento sensório motor de deficientes. A prova de conceito contribui também para a modernização de ferramentas utilizadas pelas instituições para promoção do desenvolvimento da cognição, com a inclusão de sistemas eletrônicos em seus acervos. A promoção do desenvolvimento sensório-motor avançado e das aptidões dos deficientes é alcançada através de soluções baratas, baseadas em tecnologias de Engenharia Elétrica.

O público-alvo deste trabalho são os deficientes assistidos e os técnicos especialistas das duas instituições parceiras, o Centro Cultural Louis Braille de Campinas (Braille) e a Therapies Serviços de Fisioterapia e Terapia Ocupacional LTDA (Therapies). Estas instituições têm foco no trabalho assistivo e de recuperação aos deficientes visuais e físicos da região de CampinasSP.

\section{MÉTODO}

\subsection{Parcerias com instituições de apoio}

Os projetos de extensão da PUC-Campinas caracterizam-se por realizarem ações intervencionistas junto à grupos sociais e comunidades organizadas da região metropolitana de Campinas, realizadas através do estabelecimento de parcerias formais com instituições reconhecidas atuantes nas áreas sinérgicas às diretrizes da Pró Reitoria de Extensão e Assuntos Comunitários (PROEXT). O universo destas instituições varia desde privadas até órgãos públicos, organizações não governamentais (ONGs) e organizações da sociedade civil de interesse público (OSCIP). Os resultados descritos neste trabalho são frutos de uma parceria colaborativa com o Centro Cultural Louis Braille de Campinas (Braille) e a Therapies Serviços de Fisioterapia e Terapia Ocupacional LTDA (Therapies). Estas instituições têm foco no trabalho assistivo e de recuperação aos deficientes visuais e físicos da região de Campinas-SP

\subsection{Resumo do método de intervenção social}

O método para a elaboração e construção de uma ferramenta de apoio ao desenvolvimento cognitivo de deficientes baseia-se em três (3) aspectos principais: 1) apropriação de conhecimento; 2) desenvolvimento da prova de conceito; e 3) geração de material cultural. 1) Apropriação de conhecimento: a ideia norteadora desse método é a motivação em colaborar para promover a inclusão social do público alvo através da construção de soluções tecnológicas prezando pela participação direta dos mesmos na problematização das necessidades. 2) Desenvolvimentos da prova de conceito: o desenvolvimento da prova de conceito segue um 
modelo cíclico, inspirado no Rational Unified Process (RUP), de desenvolvimento de soluções de software fundamentado em requisitos técnicos funcionais e não funcionais obtidos junto ao público alvo. O RUP atualmente é conhecido como IBM Rational Software (IBM, 2019). Os desenvolvimentos foram realizados nos laboratórios da universidade e validados em rodas de conversa específicas. 3) Geração de material cultural: o material cultural desenvolvido consiste em manuais relativos à construção, uso e operação da solução desenvolvida. $\mathrm{O}$ principal desafio é escolher uma forma de publicação que seja a mais indicada para o público alvo. Via de regra, quando este público tem alto letramento a forma mais conveniente é a escrita, por outro lado, nas situações de baixo letramento, áudio manuais são bastante recomendados.

Pensado assim, o método configura-se então numa sequência de ciclos dialógicos fundamentados em 3 ações: a) Rodas de Conversa, b) Trabalho Colaborativo e c) Apropriação de Conhecimento. a) Rodas de Conversa - a principal ferramenta para apropriação de conhecimentos, as rodas de conversas se sustentam na necessidade da problematização e de debates acerca de tema comum aos participantes. É neste ponto do ciclo que fica mais evidente a necessidade da superação das diferenças de linguagem, constituindo uma oportunidade ímpar para o desenvolvimento da competência em comunicação plena. b) Trabalho Colaborativo - no momento em que se menciona a expressão "trabalho colaborativo", pressupõe-se uma atividade em que a participação do público alvo do projeto de extensão seja realmente valiosa, isto é, busca-se que esse grupo da sociedade participe dos momentos de decisão, solução, aprimoramento e avaliação do kit. Com isso, cabe aos integrantes vindo de dentro da universidade a sintetização de seus conhecimentos no momento de difundir informações ao público e a tratamento ao recebê-las novamente em prol do objetivo comum. O público alvo, por sua vez, contribui com todo o conhecimento adquirido pela vivência das dificuldades e adaptações realizadas com objetivo de superar as limitações. Este conhecimento não se desenvolve dentro dos muros da universidade. Estabelece-se assim uma via de duas mãos que enriquece o processo educativo dos participantes. c) Apropriação de Conhecimento - nesta ação efetiva-se a parte mais rica do trabalho, quando a universidade retorna à sociedade o investimento recebido. O retorno ocorre na forma de apropriação de conhecimentos, no momento em que a sociedade toma para si os desenvolvimentos, as informações, modelos, planos, propostas etc., os resultados do projeto.

Este método de intervenção social, fundamentado na execução de três modelos: Modelo de Apropriação de Conhecimentos, Modelo de Desenvolvimento da Prova de Conceito e Modelo de Geração do Material Cultural é descrito detalhadamente em Sistema Autônomo para Travessia de Deficientes Visuais em Semáforos de Mário Joaquim de Lemes Neto e Amilton da Costa Lamas (LEMES NETO, 2018). A descrição completa do processo de geração de material cultural pode ser encontrada no artigo "Projeto Final e Extensão - Compartilhando Estratégias e Resultados de Engenharia Elétrica” (FREITAS, 2017).

\section{RESULTADOS E DISCUSSÕES}

\subsection{Requisitos funcionais e não funcionais}

Enquanto os assistidos pela Therapies são essencialmente crianças com paralisia cerebral que não possuem redução significativas de visão, mas que tem severas limitações motoras, o público do Centro Braille é composto de jovens e adultos, inclusive de terceira idade, que possuem baixa visão e consequentes limitações de habilidades físicas, dependendo de como, quando e da gravidade da redução da visão.

Após sucessivas rodadas de conversa com o público alvo, aplicadas conforme o método descrito acima, concluiu-se que a forma mais apropriada para estimular os deficientes a 
exercitarem e desenvolverem suas capacidades sensório-motoras de uma forma lúdica deveria envolver a participação ativa entre eles em um jogo de alta interatividade, na linha de um jogo competitivo, com nível de dificuldade selecionável. Os requisitos colocados pela equipe de profissionais das instituições parceiras incluíam, mas não se limitavam, a necessidade de estímulos ópticos e auditivos versáteis, portabilidade e alta interatividade, de forma que os deficientes colocassem desafios entre si. A solução deveria ser programável permitindo que as equipes de profissionais pudessem usar a solução para avaliação do nível deficiência sensóriomotora e para a construção de programas de reabilitação. Estipulou-se também que a responsividade da prova de conceito deveria indicar, de forma inequívoca, o resultado da ação tomada pelo participante do jogo.

Embora alguns requisitos fossem comuns ou adaptáveis, em alguns casos as necessidades eram antagônicas, enquanto para a Therapies era necessário que a solução não exigisse uma motricidade fina, o Braille gostaria de ter justamente o oposto. O reconhecimento da diversidade de condições de contorno levou a definição de que o jogo deveria ter diferentes características físicas para atender um público com deficiências variadas, mantendo a especificação comum de ser um jogo portátil e que pudesse ser jogado em qualquer superfície. Consequentemente foram criadas duas versões adequadas ao público de cada uma das instituições parceiras.

\subsection{Arquitetura da solução}

Em meio ao processo colaborativo de projeto da prova de conceito chegou-se à definição de que o jogo deveria ser composto por duas torres móveis, interligadas por um sistema de comunicação sem fio (WIFI), cúbicas e transparentes e que as faces deveriam se iluminadas com cores escolhidas pelos usuários. Após a apresentação física da primeira versão da prova de conceito os técnicos especialistas das instituições parceiras denominaram o sistema de ModalCube.

O ModalCube, em sua versão final, consiste em um jogo eletrônico onde dois jogadores tentam repetir a sequência face/cor dos cubos até que um erre. A prova de conceito é composta então por dois cubos transparentes com LEDs endereçáveis nas quatro faces laterais, cujas cores e intensidade luminosas são programáveis externamente. Cada uma das faces laterais possui sensores de sinalização de escolha.

A arquitetura de comunicação entre os cubos é bidirecional sem fio e segue o modelo master-slave onde o jogador com o cubo master toma a iniciativa da definição da sequência de cores e das faces, enquanto que e o jogador com o cubo slave tenta repetir a sequência (cor/face iluminada) transmitida. Os acertos ou erros são confirmados por uma sequência de cores específica (programável) acompanhada de sinalização audível. O ModalCube pode ser jogado por uma única pessoa (modo individual), neste caso o cubo master é pré-programado para uma dada sequência de cores e faces iluminadas e o deficiente tenta repetir a dupla face/cor. $\mathrm{O}$ modo individual serve o propósito de treinar o deficiente no desenvolvimento de suas habilidades motoras a partir de estímulos multissensoriais através de uma programação definida pelo técnico especializado. O jogo se encerra quando um dos jogadores comete um erro na sequência cor/face.

A Figura 1, apresenta um esquema da arquitetura da solução. Cada um dos cubos do ModalCube é composto por uma CPU (Arduino) conectada a um Módulo de Interface, um Módulo de Comunicação e um Módulo de Alimentação. A CPU contém toda a lógica de programação do jogo, inserida através da porta de entrada $(\mathbf{P})$, identifica se as respostas estão corretas ou não e envia ao Módulo de Interface e ao Módulo de Comunicação o código correspondente. O Módulo de Interface apresenta ao usuário o par face/cor ou a indicação do 
erro, dependendo do código recebido e captura a resposta do jogador via os sensores $(\mathbf{S})$. O Módulo de Comunicação é responsável pelo envio e recebimento dos códigos gerados pela CPU.

Figura 1 - Arquitetura esquemática da ModalCube.

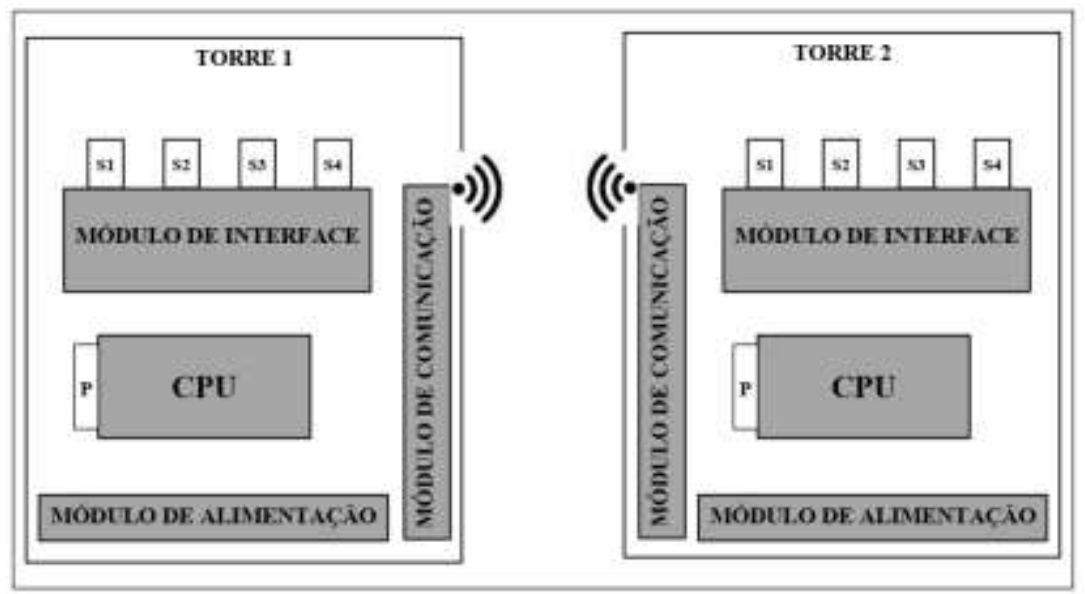

Fonte: Autores

\subsection{Sequência de jogo}

No início do jogo o cubo master toma a iniciativa de começar as jogadas. O jogador inicia escolhendo qual das quatro faces será iluminada pressionando o sensor correspondente. Esta informação, capturada pelo Módulo de Interface é repassada para a CPU a qual responde ao Módulo de Interface enviando o código da cor a ser apresentada e o Módulo de Interface acende o LED correspondente na cor pré-programada. Na sequência, a CPU repassa para o Módulo de Comunicação o código referente à dupla face/cor, o qual, por sua vez, transmite ao cubo slave a informação. No cubo slave o Módulo de Comunicação recebe a informação e passa para a sua CPU, a qual, informa ao Módulo de Interface qual face deve ser iluminada e com qual cor. O Módulo de Interface ilumina a face definida com a cor escolhida, esperando pela resposta do jogador. Se o jogador acertar a sequência este deve incluir um novo par face/cor a ser transmitido para o cubo master e o jogo continua, aumentando o tamanho da sequência face/cor. Em caso de erro a CPU, após identificar o código errado, envia para o Módulo de Interface do seu cubo o código correspondente a resposta errada e o cubo slave indica o erro através de uma sequência de cores e sinalização audível.

\subsection{Programa de Desenvolvimento Cognitivo}

Programas de desenvolvimento sensório-motor utilizando ModalCube consistem na definição e posterior repetição de uma sequência de faces iluminadas e cores até ocorrer em erro, escolhendo uma face equivocada. Eles podem ser realizados de duas (2) formas: 1) modo competição - neste caso o ModalCube é usado por dois deficientes ou um deficiente e um técnico, que competem entre si pelo acerto da face iluminada, No caso de um dos jogadres for um técnico este deve ficar com o cubo master e iniciar o jogo. 2) modo treinamento - neste modo o operador (técnico) carrega uma sequência nas CPUs utilizando uma porta de entrada e deficiente segue a sequência de cores/faces pré-estabelecida. 


\subsection{Preparação e programação do ModalCube}

Antes de iniciar qualquer atividade com a prova de conceito é necessário programar as cores que acenderão em cada face lateral dos cubos. A programação é feita carregando via PC um programa externo na CPU de cada torre.

Os manuais de programação, uso, operação e construção, entregues para as instituições parceiras, descrevem detalhadamente os passos necessários para a realização de cada um dos processos.

\subsection{Material Cultural}

Um dos principais objetivos do programa de extensão da PUC Campinas é a devolutiva para a sociedade do investimento realizado na instituição. Neste caso a devolutiva é feita através da apropriação dos conhecimentos, métodos e processos desenvolvidos durante o projeto. Especificamente as instituições parceiras recebem treinamento na operação da prova de conceito e todos os manuais necessários para a replicação, manutenção, operação e desenvolvimento de programas de treinamento, avaliação e reabilitação sensório-motora de seus assistidos. São repassados também todas as listagens e programas de software necessários para a construção de programas de desenvolvimento.

\subsection{Demonstração da prova de conceito (ModalCube)}

Após a realização de múltiplos ciclos dialógicos com as instituições parceiras foi concretizada a versão final do ModalCube, um sistema de apoio ao desenvolvimento sensóriomotor de deficientes que atende aos requisitos definidos colaborativamente. A Imagem 1 mostra o sistema e operação

Imagem 1 - ModalCube em operação.

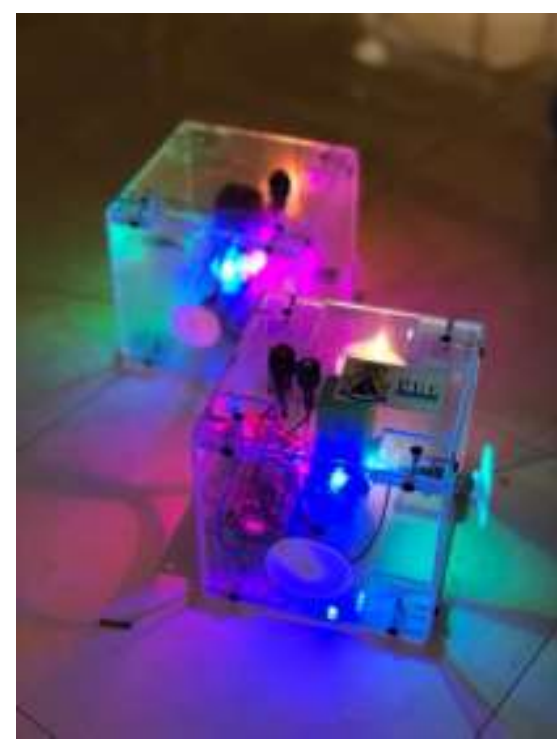

Fonte: Autores

Após o último ciclo das rodas de conversa a prova de conceito foi validada pelos técnicos das instituições parceiras e demonstrada no evento de encerramento do projeto. A Imagem 2 mostra o uso do ModalCube durante o evento. 


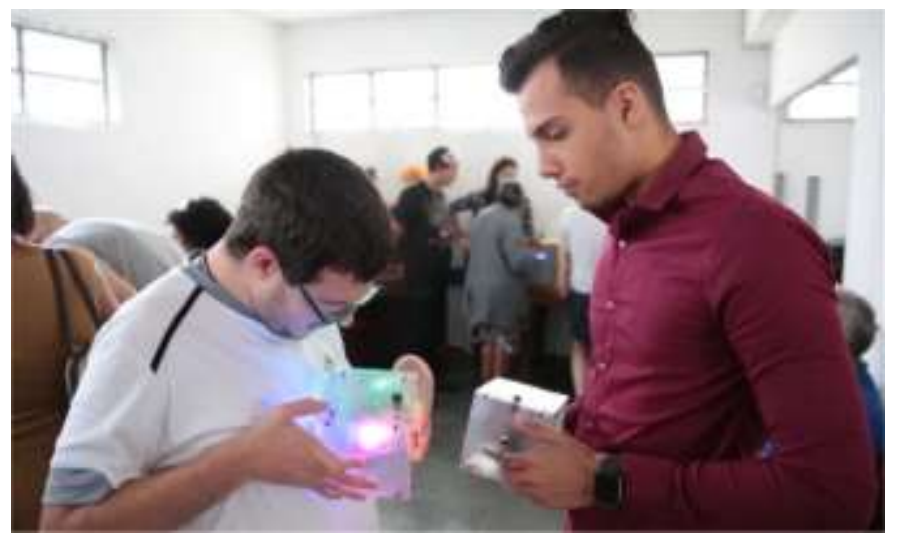

Fonte: Autores

Visando contemplar as diferenças entre os requisitos apontados pelas instituições desenvolveu-se um segundo modelo da prova de conceito em que os botões grandes foram substituídos por menores. Isto se deu porque o Centro Braille optou por desenvolver a motricidade fina em seus assistidos, enquanto que os assistidos pela Therapies não indicaram prioridade alguma para este desenvolvimento.

\subsection{Impacto na formação do discente}

A participação no projeto de extensão permitiu ao discente identificar, projetar e analisar sistemas, produtos e processos na área de Engenharia Elétrica/Mecânica, exercitando a formulação e solução de problemas de engenharia. A participação também promoveu a aplicação dos conhecimentos de software e hardware, no desenvolvimento de sistemas informatizados, o desenvolvimento dos princípios éticos que orientam a conduta profissional do engenheiro e a exploração da aplicabilidade de soluções no mundo das pessoas com mobilidade prejudicada; da mesma forma oportunizou a análise crítica da construção do ser humano, permitindo a vivência de desafios contemporâneos articulando abordagens relativas a questões de direitos humanos do multiculturalismo, da identidade e das relações étnico-raciais.

À medida em que as habilidades de engenharia se tornam uma commodity, os programas de Engenharia Elétrica/Mecânica são instados a adaptar suas estratégias pedagógicas com objetivo de melhor preparar seus graduados. Espera-se que os engenheiros do século XXI tenham uma base técnica forte, ao mesmo tempo em que sejam capazes de trabalhar com pessoas com diferentes tipos de capitais intelectuais e sociais e ter um alto nível de flexibilidade cognitiva. Neste projeto o discente participante realizou atividades de extensão simultaneamente com as classes regulares. Neste caso, as atividades dizem respeito ao coplanejamento e co-criação/execução de serviços e/ou aplicações, soluções, provas de conceito, protótipos, inovadores fundamentados em tecnologias desenvolvidas nas disciplinas do curso, num formato colaborativo entre estudantes de engenharia elétrica, técnicos sociais e assistidos. O estudante, participante do projeto, tem a oportunidade de desenvolver suas habilidades de comunicação, análise e interpretação de dados, vivências relacionamentos de forma não disponível na sala de aula. Ele também experimentou resolver situações de conflito e encontrar usos criativos e aplicações para o conhecimento não previstos dentre os muros da universidade. Através desta experiência, o graduando de engenharia desenvolveu um sentido maior de responsabilidade com a sociedade e uma melhor compreensão do que significa ser um engenheiro. A participação no Projeto de Extensão também trouxe várias oportunidades de reconhecimento profissional pelos técnicos e pelos assistidos, o que estimulou o aluno a alcançar um melhor desempenho no curso. 


\section{CONSIDERAÇÕES FINAIS}

Neste artigo apresentou-se a ideação e a construção/validação de uma prova de conceito de um sistema de apoio ao desenvolvimento sensório-motor de deficientes baseada em estímulos visuais com ampla variedade e controle de cores. Possuindo dois modos de operação o sistema, nomeado ModalCube pelos deficientes, permite o uso individual ou em duplas, em formatos de competição ou treinamento.

O desenvolvimento colaborativo, típico de projetos de extensão, permitiu que as ideias dos técnicos especializados e dos próprios deficientes fossem incluídas no resultado final, seja na forma de requisitos funcionais ou não funcionais. O sistema utiliza conceitos de gamificação, o que torna o desenvolvimento das capacidades sensório-motoras e os testes de avaliação lúdicos e prazerosos de serem realizados.

As instituições parceiras se mostraram bastante motivadas por terem incorporado em seus acervos de ferramentas uma solução simples que apoia o desenvolvimento e avaliação cognitiva de deficiente construída especificamente para as suas necessidades. Esta é uma consequência natural do desenvolvimento colaborativo

\section{Agradecimentos}

Os autores agradecem o suporte da Pró-Reitoria de Extensão e Assuntos Comunitários (PROEXT) da PUC-Campinas; das instituições parceiras deste projeto de extensão, o Centro Cultural Louis Braille de Campinas (CCBLC) e a Therapies Serviços de Fisioterapia e Terapia Ocupacional LTDA (Therapies); dos especialistas da área de saúde e educação das instituições parceiras, na pessoa da Fabiana Pazinatti (pedagoga), da Juliana Nicomedes (Terapeuta Ocupacional) e da Alessandra Montoan (Terapeuta Ocupacional); dos colaboradores dos laboratórios de Eletrônica e Meios de Comunicação e da Maquetaria da PUC-Campinas.

\section{REFERÊNCIAS}

BRANDÃO MB et ali., Functional priorities reported by parents of children with cerebral palsy: contribution to the pediatric rehabilitation process. Braz J Phys Ther. Nov-Dec; v.18, n.6, p. 563-571, 2014.

BRASIL. Decreto-Lei no 3.298, de 20 de dezembro de 1999. Disponível em: http://www.planalto.gov.br/ccivil_03/decreto/d3298.htm . Acesso em: 05 mai. 2020.

BRASIL. Lei $\mathbf{n}^{\mathbf{0}} \mathbf{7 . 8 5 3}$, de 24 de outubro de 1989. Dispõe sobre o apoio às pessoas portadoras de deficiência, sua integração social, sobre a Coordenadoria Nacional para Integração da Pessoa Portadora de Deficiência - Corde, institui a tutela jurisdicional de interesses coletivos ou difusos dessas pessoas, disciplina a atuação do Ministério Público, define crimes, e dá outras providências. Disponível em: http://www.planalto.gov.br/ccivil_03/leis/L7853.htm . Acesso em: 05 mai. 2020.

FREITAS, D. E. et ali, Projeto Final e Extensão - Compartilhando Estratégias e Resultados de Engenharia Elétrica - Anais do $45^{\circ}$ Congresso Brasileiro de Educação em Engenharia - COBENGE 2017. Disponível em: http://www.abenge.org.br/sis_artigos.php. Acesso em: 08 mai. 2020. 
FELICETTI, S e SANTOS, E. Tecnologias assistivas, cegueira, baixa visão, paralisia cerebral: uma revisão da literatura. Revista Tecnologia e Sociedade, v12, n.24, p. 1-29, 2016.

IBGE - Censo Demográfico, Características gerais da população, religião e pessoas com deficiência. Rio de Janeiro, p.1-215, 2010. Disponível em:

https://biblioteca.ibge.gov.br/visualizacao/periodicos/94/cd_2010_religiao_deficiencia.pdf . Acesso em: 04 jun. 2020.

IBM. Rational Software, 2014. Disponível em:

https://www01.ibm.com/software/br/rational/ . Acesso em: 08 mai. 2020.

LEMES NETO, Mário Joaquim, LAMAS, Amilton da Costa 2018 - Sistema Autônomo para Travessia de Deficientes Visuais em Semáforos, VI Jornada de Extensión Universitária del Mercosur, 2018, Tandil. 24-27 de abril 2018 ISBN: 978-950-658-448-1. Disponível em: http://extension.unicen.edu.ar/jem/Libro_JEM_2018.pdf . - página 40. Argentina, 2018. Acesso em: 08 jun. 2020.

NOVAC, I - Evidence-Based Diagnosis, Health Care, and Rehabilitation for Children With Cerebral Palsy, Journal of Child Neurology, v29, n.8, p. 1141-1156, 2014.

\title{
SENSORY MOTOR SKILLS DEVELOPMENT DEVICE FOR THE HANDICAPPED
}

\begin{abstract}
Cerebral palsy in children and vision impairment in adults and older people can lead to difficulties in motricity, cognition, and autonomous mobility. Such disabilities can be overcome by training and proper rehabilitation programs performed at specialized institutions. Very few clinics and supporting handicapped institutions can afford to have specially designed tools and equipment to implement such rehabilitation programs or even evaluate the level of disability. This work reports on the collaborative development of a game like a system designed to make feasible the pleasurable participation in sensory-motor skills rehabilitation programs by the handicapped. The systems consist of two transparent plastic cubes linked in a full-duplex network in a master-slave architecture. Both cubes have addressable RGB LEDs in each of the four lateral faces. The game-like rehabilitation program consists of replicating the color/face sequence defined by the opponent. The system can also be played in a programed mode, where a health technician can define a face/color sequence to be followed. This allows the handicapped to practice color recognition and upper members exercises. The Centro Cultural Louis Braille de Campinas and Therapies Serviços de Fisioterapia were partners of the project.
\end{abstract}

Key-words: cerebral palsy, collaborative method, handicapped, sensory-motor skills, university extension project. 